\title{
Alih Teknologi Trouble Shooting Komputer Untuk Ikatan Pemuda Muhammadiyah, Beji, Depok
}

\author{
Haolia $\mathbf{R}^{\mathbf{1}}$, Sidiq $\mathbf{R}^{\mathbf{1}}$, Candra $\mathrm{D}^{\mathbf{1}}$, Hasvienda $\mathrm{M}^{\mathbf{1}}$, Asep $\mathrm{Y}^{\mathbf{1}}$ \\ ${ }_{1}^{1}$ Prgram Studi D-3 Teknik Mesin, Jurusan Teknik Mesin, Politeknik Negeri Jakarta
}

\begin{abstract}
Abstrak
Kekuatan manusia terletak pada akal pikirannya. Berdasarkan latar belakang ini, maka manusia harus senantiasa terus berinovasi berbuat banyak agar bermanfaat bagi masyarakat dan lingkungan. Salah satu ikhtiar manusia guna mencapai keberhasilan inovasinya ialah dengan mengaplikasikan gagasan menjadi bentuk nyata. Dengan bantuan teknologi, manusia semakin mudah mencapai setiap tujuannya, misalnya dengan hadirnya gawai semakin mempermudah manusia dalam melakukan aktivitas sehari-hari khususnya segala sesuatu yang berkaitan dengan pekerjaan atau aktifitas sehari-hari. Program Studi D-3 Teknik Mesin, Jurusan Teknik Mesin Politeknik Negeri Jakarta melaksanakan suatu terobosan dalam memanfaatkan teknologi yakni dengan mengadakan kegiatan pengabdian kepada masyarakat guna menggali manfaat eksistensi Perguruan Tinggi sebagai wadah para akademisi dalam mengaplikasikan Tri Darma Perguruan Tinggi.

Tema Pengabdian Masyarakat D-3 Teknik Mesin adalah mengenai Trouble Shooting komputer yang dilaksanakan di SMA 2 Muhammadiyah Beji Depok. Adapun pesertanya ialah para pemuda Muhammadiyah yang keseluruhannya juga merupakan siswa SMA ini. Tujuan Pengabdian masyarakat bagi peserta adalah peningkatan wawasan dan keterampilan peserta dalam dalam trouble shooting komputer khususnya dalam amteri instal ulang windows 7 dan cara melakukan reset password pada komputer. Adapun upaya dari program ini ialah membekali isswa dengan modul dan flaskdisk yang di dalamnya sudah terdapat software windows 7 dan beberapa komponen.
\end{abstract}

Kata Kunci: komputer, trouble shooting, dan pemuda

\begin{abstract}
It is believed that human strength lies in the human mind. Based on this background, human beings must constantly innovate to do much to benefit of the community and the environment. One of the human efforts to achieve the success of innovation is to apply ideas into tangible forms. With the help of technology, it is easier for humans to achieve each of their goals like for example with the presence of a useful device. D-3 Study Program Mechanical Engineering, Department of Mechanical Engineering Politeknik Negeri Jakarta (PNJ) implements a breakthrough utilized technology by organizing a Community Service in a higher education of whom academics to apply the Tri Darma of Higher Education. The theme is about how to deal weith the Trouble Shooting computer which is held at SMA 2 Muhammadiyah Beji Depok. The participants were Muhammadiyah youths, all of whom were high school students. The main aim of community service for participants is to increase the participants' insights and skills in computer trouble shooting, especially in the wife reinstalling Windows 7 and how to reset the password on the computer. The effort of this program is to provide issues with modules and flask disk which already have Windows 7 software and some components.
\end{abstract}

Keywords: computers, trouble shooting, and youth 


\section{PENDAHULUAN}

\section{Analisis Situasi}

Era Revolusi Industri 4.0 menuntut sumber daya manusia (SDM) untuk selalu meningkatkan skill dalam setiap bidang, atau lebih tepatnya hidup di zaman sekarang harus memilki kemampuan berbagai bidang. Entah ilmu yang dapat dipelajari langsung pada institusi pendidikan formal maupun non formal, ataupun secara autodidak. Peran dunia pendidikan sejatinya untuk mencetak manusia agar menjadi pribadi unggul dan siap menghadapi tantangan di masa depan. Jumlah penduduk yang terus bertambah, tidak sebanding dengan bertambahnya lapangan pekerjaan, namun sumber daya manusia tetap harus ditingkatkan.

Salah satu upaya untuk meningkatakan kemampuan sumber daya manusia yakni dengan mengoptimalkan peran dunia pendidikan mulai dari jenjang sekolah hingga perguruan tinggi. Bahkan, tidak hanya pendidikan formal saja yang berperan untuk meningkatkan skill, pendidikan non formal juga memilki peran strategis untuk meningkatkan kualitas sumber daya manusia. Perguruan tinggi sebagai rumah kaum intelektual (dosen) memilki tiga peran, yakni pendidikan, penelitian dan pengabdian. Namun yang bersentuhan langsung dan manfaatnya dirasakan oleh masyarakat yakni program pengabdian yang dilaksanakan oleh Program Studi D-3 Teknik Mesin, Jurusan Teknik Mesin, Politeknik Negeri Jakarta.

\section{Program Studi Teknik Mesin, Jurusan}

Teknik Mesin, Politeknik Negeri Jakarta, tepatnya pada Sabtu 07 September 2019 telah melakukan kegiatan pengabdian kepada masyarkat dengan mengusung tema 'Alih Teknologi Trouble Shooting Komputer untuk Ikatan Pemuda Muhammadiyah Beji Depok.' Lokasi pelatihan ini dilaksanakan di SMA 2 Muhammadiyah Beji dari latar belakang pelajar. Adapun pemateri pelatihan diisi oleh dosen Teknik Mesin Politeknik Negeri Jakarta, yakni Haolia Rahman, Ph.D., dan Hasvienda Mohammad Ridlwan, S.T., M.T. Kegiatan yang berlangsung di laboratorium komputer SMA 2 Muhammadiyah Beji ini dimulai pukul 08.00 wib dan selesai pukul 12.00 WIB.
Setiap peserta selain dibimbing tentang cara menginstal ulang windows komputer secara bertahap, mereka juga dibekali modul dan flasdisk yang sudah terisi software instalasi windows 7 agar mempermudah dalam melakukan praktiknya. Satu perangkat komputer untuk satu peserta, supaya materi yang diperoleh dapat langsung dipraktikkan.

Para peserta sangat antusias engikuti pelatihan Trouble Shooting yang isi materinya lebih difokuskan tentang bagaimana cara menginstal ulang windows 7 komputer dan cara melakukan reset password. Dari awal pelatihan hingga selesai tidak sedikit peserta yang begitu gembira dan bahkan ada yang berharap pelatihan ini dilaksanakan lebih dari satu hari dengan materi yang berbeda. Hal ini diungkapkan oleh salah satu peserta pelatihan Muhammad Haydar Ilham Kamil pada penulis.

Politeknik Negeri Jakarta khususnya Jurusan Teknik Mesin, Program Studi Teknik Mesin, akan selalu bersinergi dengan masyarakat sekitar agar eksistensi dan manfaat lembaga pendidikan tinggi dapat dirasakan langsung oleh masyarakat. Selain itu, juga diharapkan dengan adanya program pengabdian ini semakin menambah kepedulian kaum akademis, khususnya para dosen agar lebih peduli dengan masyarakat sekitar.

Pelatihan Trouble Shooting komputer ini diharapkan agar menambah potensi para pemuda (pelajar) sebagai peserta pelatihan untuk dapat mengatasi komputer bermasalah-termasuk di dalamnya menginstal ulang windows, dan diharapkan output pelatihan ini terus dikembangkan hingga peserta mahir dalam mengatasi komputer. Apalagi saat ini hampir segala bentuk aktifitas membutuhkan perangkat kompter (laptop) untuk mempermudah pekerjaan.

Selain itu, manfaat dari pelatihan sangat dirasakan oleh peserta, terbukti dari kuesioner yang diisi oleh peserta, antara sebelum dan setelah pelatihan, peningkatan kemampuannya cukup signifikan. 
Jika keampuan para peserta sudah ahli dalam memparaktikkan sendiri install ulang komputer, diharapkan mampu menjadi wawasan baru bagi para peserta.

\section{Permasalahan}

Permasalahan yang dihadapi oleh para peserta adalah:

1) Masih kurangnya pengetahuan tentang trouble shooting dalam hal ini teknik penguasaan permasalah utama pada komputer, seperti komputer mati atau tidak bisa masuk windows.

2) Rendahnya pemahaman para peserta tentang trouble shooting komputer terutama mengenai install ulang komputer windows 7.

3) Kurangnya pemahaman trouble shooting komputer terutama mengenai reset password.

\section{TARGET DAN LUARAN}

\section{Target yang ingin dicapai}

Dengan diadakannya pelatihan ini,
diharapkan terjadinya peningkatan
pengetahun dan kemampuan para peserta pelajar
(pemuda) yang sekaligus sebagai

bekal peserta untuk mencari solusi memperbaiki komputer yang rusak, supaya

tidak mengandalkan pihak eksternal dalam proses perbaikan. Selain itu, untuk

menunjang serta bentuk pendalaman pengetahuan dalam materi komputer yang

telah diperoleh dari bangku sekolah.

\section{Luaran yang ingin dicapai}

Adapun luaran yang diharapkan

adalah publikasi ilmiah dalam bentuk artikel yang dipublikasikan di media massa, sehingga dapat dibaca oleh masyarakat luas, baik dari lingkungan perguruan tinggi maupun masyarakat umum.

\section{METODE PELAKSANAAN}

Kegiatan pelatihan trouble shooting ini dilaksanakan kepada para peserta yaitu kelompok para pelajar (pemuda) Muhammadiyah Beji, Depok.
Metode yang dilaksanakan untuk mencapai tujuan adalah:

1) Metode yang digunakan dalam kegiatan pelatihan trouble shooting komputer kali ini ialah participant active learning (peserta berpartisipasi secara aktif dalam kegiatan pelatihan interaktif dan pendampingan pengaplikasian trouble shooting komputer). Selain peserta dibekali modul, dihadirkan pula instruktur yang memandu proses jalannya kegiatan pelatihan trsebut dengan dibantu oleh para mahasiswa Jurusan Teknik Mesin PNJ agar kegiatan pelatihan berjalan kondusif. Peserta pelatihan berjumlah 32 orang yang berasal dari siswa kelas XI SMA 2 Muhammadiyah Beji Depok yang tercatat juga sebagai pemuda Muhammadiyah Beji Depok. Semama pelatihan berlangsung, instruktur memastikan tidak ada satu peserta pun yang tidak mengikuti proses pemahaman teori dan aplikasinya.s sehingga, satu orang peserta mengoperasikan satu perangkat komputer.

2) Pada pelaksanaan pelatihan, demontrasi media (komputer dan pprojector), selain itu peserta dibekali modul yang digunakan untuk menyampaikan materi pelatihan, seperti: membuat langlah- langkah melukukan install windows 7 dengan menggunakan aplikasi software windows 7 dan cara meresset password komputer.

3) Selanjutnya, metode tanya jawab antara instuktur dan para peserta merupakan suatu cara penyampaian materi untuk pelatihan yang dilakukan dengan tujuan memberikan kejelasan suatu informasi atau pengetahuan serta konsep materi dengan cara mengajukan pertanyaan dan dijawab oleh pihak lain

4) Metode diskusi, dengan cara membagi anak menjadi 2-3 orang per unit komputer untuk membagi pemahaman agar materi mampu dipahami oleh seluruh peserta adalah kegiatan yang dilakukan dengan melibatkan peserta pelatihan dan pendampingan dalam membahas dan memecahkan permasalahan yang ditugaskan dalam kegiatan pelatihan dan pendampingan sehingga ada kegiatan saling bertukar pikiran.

5) Praktik merupakan kegiatan yang dilakukan peserta pelatihan dan pendampingan dimana peserta melakukan praktik secara langsung dalam pendampingan pengaplikasian komputer dengan arahan fasilitator.

6) Kuesioner merupakan instrumen penelitian berupa kuisioner. Kuisioner dibagi dalam 2 sesi yakni diberikan sebelum pelatihan (pre test) dan setelah pelatihan (post test). Untuk menetapkan keabsahan data diperlukan kriteria pemeriksaan data berupa kriteria derajat kepercayaan. Hal ini dilakukan untuk menjaga kredibilitas hasil penelitian yang dilakukan. Validasi yang 
digunakan untuk menjaga kredibilitas ini adalah triangulasi.

Analisis data dilakukan melalui tiga jalur kegiatan yang berjalan secara simultan. Ketiga jalur ini adalah (1) reduksi data, yakni proses pemilihan, pemusatan, perhatian pada penyederhanaan, pengabstrakan, dan transformasi data kasar yang muncul dari catatan-catatan tertulis di lapangan; (2) penyajian data, yakni penyajian informasi yang telah tersusun yang kemungkinan memberikan penarikan kesimpulan dan pengambilan tindakan; dan (3) penarikan kesimpulan atau verifikasi, dalam kegiatan ini peneliti mencari arti benda-benda, mencatat urutan, dan pola-pola dari permulaan pengumpulan data.

\section{HASIL DAN PEMBAHASAN Hasil Kegiatan}

Kegiatan pengabdian kepada masyarakat ini dilaksanakan di Ruang Laboratorium Komputer SMA 2

Muhammadiyah Beji, Depok. Sebelum acara dimulai, terlebih dahulu panitia mempersilakan para peserta untuk menyimak samabutan dan mengisi kuesioner pra pelaksanaan pelatihan Trouble Shooting Komputer.

Kegiatan yang dilakukanoleh Tim dosen Program Studi Teknik Mesin, Jurusan Teknik Mesin Politeknik Negeri Jakarta ini dirasakan manfaatnya oleh para peserta. Selain itu, antusiasme peserta selama mengikuti kegiatan ini, terlihat dari feed back yang diberikan oleh peserta melalui banyaknya pertanyaan- pertanyaan yang diajukan oleh ibu-ibu kepada narasumber.

Para peserta sangat tertarik melihat media tanam yang ada pada kegiatan ini. Selain itu para peserta juga sangat senang dengan adanya program pelatihan trouble shooting komputer yang mencakup materi install ulang windows 7 reset password komputer.

\section{Pembahasan}

Dalam melaksanakan kegiatan pengabdian masyarakat ini, panitia membuat kuesioner sebagai alat ukur yang diisi sebelum dan sesudah acara dilaksanakan. Hasil pengukuran sebelum dan sesudah kegiatan ditampilkan pada Tabel berikut ini.

\begin{tabular}{|c|c|c|c|}
\hline No & Pertanyaan & $\begin{array}{r}\text { Resp } \\
Y\end{array}$ & $\begin{array}{c}\text { Resp } \\
\mathrm{N}\end{array}$ \\
\hline 1 & $\begin{array}{l}\text { Apakah Anda } \\
\text { mampu } \\
\text { mengoperasik } \\
\text { an komputer }\end{array}$ & $95 \%$ & $5 \%$ \\
\hline 2 & $\begin{array}{l}\text { Apakah Anda pernah } \\
\text { mendengar istilah } \\
\text { Trouble } \\
\text { komputer }\end{array}$ & $5 \%$ & $95 \%$ \\
\hline 3 & $\begin{array}{l}\text { Apakah Anda } \\
\text { pernah } \\
\text { mengikuti } \\
\text { pelatihan }\end{array}$ & $0 \%$ & $\begin{array}{l}100 \\
\%\end{array}$ \\
\hline 4 & $\begin{array}{l}\text { Apakah Anda } \\
\text { mengetaui istilah } \\
\text { Reset Password pada } \\
\text { Komputer }\end{array}$ & $20 \%$ & $\begin{array}{l}80 \\
\%\end{array}$ \\
\hline 5 & $\begin{array}{l}\text { Apakah Anda bisa } \\
\text { menginstal ulang } \\
\text { komputer }\end{array}$ & $5 \%$ & \\
\hline
\end{tabular}

Tabel 1. Hasil pengukuran sebelum kegiatan dilaksanakan 
Berdasarkan hasil pengukuran di atas menggambarkan bahwa peserta pada umumnya tertarik untuk mengikuti pelatihan Trouble shooting komputer, sebanyak rata-rata belum mampu melakukan install ulang windows pada komputer. Hal ini dikarenakan para peserta menganggap bahwa Trouble shooting komputer merupakan suatu pengalaman yang baru dalam mengoperasikan atau memperbaiki komputer yang bermasalah. Selain itu, para peserta ingin mendapatkan pengetahuan baru dalam mengoperasikan sistem komputer yang bermasalah, hal tersebut lebih, dibuktikan dengan jawaban para peserta $100 \%$ belum pernah mengikuti pelatihan tentang trouble shooting komputer ini.
Para peserta mampu mempraktikkan cara install ulang windows sesuai dengan materi yang telah diberikan oleh instruktur.

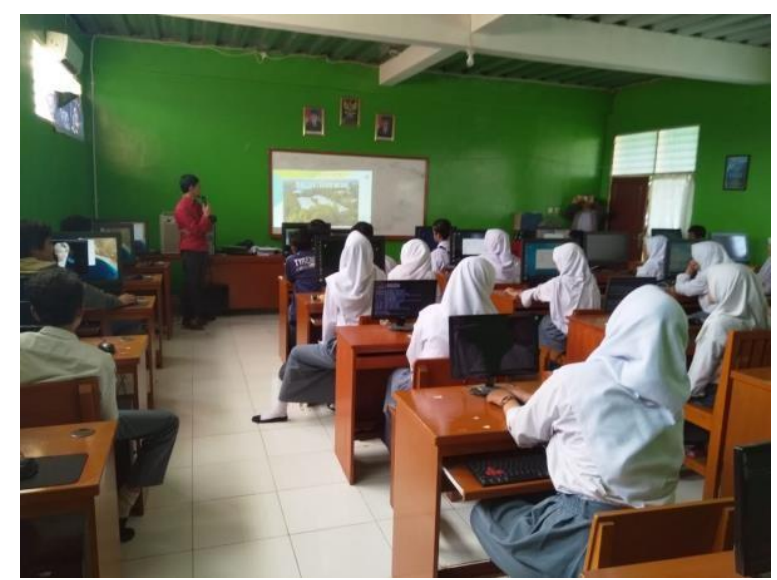

Gambar 1. Proses pelatihan alih teknologi Trouble Shooting

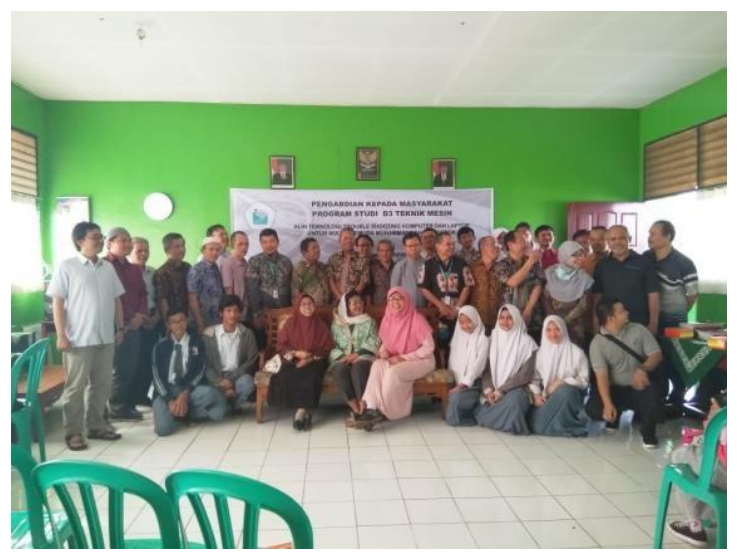

Gambar 2. Pasca pelatihan alih teknologi trouble shooting komputer

Pertanyaan yang muncul pada saat kegiatan adalah tentang proses atau tahapan trouble shooting komputer yang permanen. Instalasi window 7, cara mereset password pada windows 7 , merupakan materi trouble shooting komputer yang tidak membutuhkan tenaga yang besar, terutama alat untuk menginstal seperti yang dicontohkan.

Sedangkan instalasi Trouble shooting komputer tidak memerlukan alat yang banyak, karena peserta dapat memanfaatkan flasdisk yang telah terisi software windows 7. Salah satu contoh manfaat ke depan, peserta mampu melakukan praktik materi pelatihan dengan mengaplikasikan langsung pada komputer atau laptop milki pribadi, maupun milik orang lain. 
PelatihanTrouble shooting komputer yang disampaikan oleh Tim Jurusan Teknik Mesin PNJ adalah pelatihan yang memfokuskan pada operasi instalasi windows 7 dan cara mereset password pada windows 7, sehingga peserta yang melakukan pelatihan dapat mendalami materi secara penuh dan mampu memfokuskan materi secara mendalam.

\section{SIMPULAN.}

Pengetahuan peserta tentang alih teknologi trouble shooting, khususnya dalam hal install ulang window 7 dan reset password komputer ini dirasakan manfaatnya oleh seluruh peserta. Semua peserta dari sebelum hingga setelah pelatihan mengalami peningkatan penguasaan teori dan praktik trouble shooting komputer install ulang windows 7. Kemudian selain pemahaman yang meningkat, diharapkan juga para peserta mampu menerapkan keahliannya dalam kehidupan sehari-hari baik di sekolah maupun di tempat lain. Peningkatan pengetahuan ini disebabkan karena pelatihan yang berlangsung dilaksanakan oleh para peserta pada kegiatan ini langsung aplikasi teori yang telah dilakukan, sehingga minat untuk mempraktikkan pelatihan Trouble shooting komputer pasca kegiatan peserta juga meningkat.

Peningkatan pengetahuan ini dipantau tidak hanya pada saat mengikuti pelatihan, namun tim program studi Teknik Mesin juga melakukan pemantauan setelah kegiatan selesai ke lokasi kegiatan. Pengetahuan untuk melakukan praktik masing-masing diharapkan oleh Tim dosen Panitia Pengabdian dapat terlaksana. Akhirnya, dapat disimpulkan bahwa kegiatan ini sangat bermanfaat bagi peserta dalam mengatasi permasalan komputer, serta peserta mampu melakukan install ulang windows dan reset password pada perangkat komputer atau laptop.

Peserta berharap bahwa kegiatan alih teknologi trouble shooting komputer yang diperkenalkan tidak hanya yang selesai sampai materi yang telah didapatkan, namun materi trouble shooting komputer materi lainnya dapat diselenggarakan, agar pengetahuan para peserta mampu meningkat secara terstruktur dan signifikan.

\section{Daftar Pustaka}

Departemen Pendidikan Nasional. (2006). Rencana strategis Departemen Pendidikan Nasional 2005 - 2009: Menuju pembangunan pendidikan nasional jangka panjang 2025.

Holleman, M. (Ed.). (1990). The role of the learning resources center in instruction. San Fransisco: Jossey-Bass Inc.

Oyston, E. (ed). (2003). Centred on learning: Academic case studies on learning centre development. Aldershot, Hampshire: Ashgate Publishing Limited.

Sitepu, B.P. (2008). Pengembangan Sumber Belajar. Jurnal pendidikan Penabur. No 11 Tahun 7 2008( 79-92). Jakarta: BPK Penabur., 